\title{
Mossy Fiber Synaptic Reorganization Induced by Kindling: Time Course of Development, Progression, and Permanence
}

\author{
José E. Cavazos, Golijeh Golarai, and Thomas P. Sutula \\ Neuroscience Training Program and Departments of Neurology and Anatomy, University of Wisconsin, Madison, \\ Wisconsin 53792
}

Recent studies have revealed that mossy fiber axons of granule cells in the dentate gyrus undergo reorganization of their terminal projections in both animal models of epilepsy and human epilepsy. This synaptic reorganization has been demonstrated by the Timm method, a histochemical technique that selectively labels synaptic terminals of mossy fibers because of their high zinc content. It has been generally presumed that the reorganization of the terminal projections of the mossy fiber pathway is a consequence of axonal sprouting and synaptogenesis by mossy fibers. To evaluate this possibility further, the time course for development of Timm granules, which correspond ultrastructurally to mossy fiber synaptic terminals, was examined in the supragranular layer of the dentate gyrus at the initiation of kindling stimulation with an improved scoring method for assessment of alterations in Timm histochemistry. The progression and permanence of this histological alteration were similarly evaluated during the behavioral and electrographic evolution of kindling evoked by perforant path, amygdala, or olfactory bulb stimulation. Mossy fiber synaptic terminals developed in the supragranular region of the dentate gyrus by $4 \mathrm{~d}$ after initiation of kindling stimulation in a time course compatible with axon sprouting. The induced alterations in the terminal projections of the mossy fiber pathway progressed with the evolution of behavioral kindled seizures, became permanent in parallel with the development of longlasting susceptibility to evoked seizures, and were observed as long as 8 months after the last evoked kindled seizure. The results demonstrated a strong correlation between mossy fiber synaptic reorganization and the development, progression, and permanence of the kindling phenomenon.

Kindling is the progressive increase in electrographic and behavioral seizures evoked by periodic electrical or chemical activation of neural pathways (Goddard et al., 1969). In the kindling paradigm, repeated stimulation of neural pathways gradually evokes progressive behavioral and electrographic seizures and eventually induces a permanent epileptic state with spontaneous seizures (Pinel et al., 1974; Wada et al., 1974). As

\footnotetext{
Received Jan. 4, 1991; revised Apr. 8, 1991; accepted Apr. 16, 1991.

We gratefully acknowledge the statistical assistance of Murray Clayton, Josep Ginebra, Ernesto Monroy, and Wade Brorsen; the helpful comments of Lew Habcrly, Ronald Kalil, and Steven Kornguth; and the technical assistance of Cynthia Hurtenbach, Isabel Parada, and Edward Kanas. This research was supported by NINDS Grants K07-NS00808 and R29-NS25020.

Correspondence should be addressed to Dr. Sutula, Dept. of Neurology, H4/ 614, University of Wisconsin, Madison, WI 53792.

Copyright (c) 1991 Society for Neuroscience $0270-6474 / 91 / 112795-09 \$ 03.00 / 0$
}

the susceptibility to seizures evoked by kindling is permanent, it has been generally presumed that the cellular alterations underlying the kindling phenomenon must also be permanent. The cellular alterations induced by kindling are of considerable intcrest, as many of the features of kindled seizures resemble human epilepsy (McNamara, 1986, 1988).

Recent studies have demonstrated that kindling induces both long-lasting electrophysiological (Mody et al., 1988) and morphological alterations in limbic pathways (Sutula et al., 1988; Repressa et al., 1989; Cavazos and Sutula, 1990). The morphological alterations induced by kindling include progressive neuronal luss in the hilus of the dentate gyrus (DG) and reorganization of the mossy fiber pathway from granule cells. The axons of the granule cells, the so-called mossy fibers, normally establish synaptic contacts with a diverse population of polymorphic neurons in the hilus of the DG, and with pyramidal neurons in the CA3 and CA3c regions of the hippocampus (Blackstad and Kjaerheim, 1961; Blackstad, 1963; Amaral, 1978). The synaptic terminals of the mossy fibers can be selectively identified by Timm histochemistry because of their high zinc content (Ibata and Otsuka, 1969; Laurberg and Zimmer, 1981; Frederickson et al., 1983; Perez-Clausell and Danscher, 1985).

In a previous study, we utilized Timm histochemistry to study the effects of kindling on the pattern of mossy fiber termination. During the course of repeated kindling stimulation, Timm-labeled synaptic terminals developed in the supragranular layer of the DG, where they are not normally found (Sutula et al., 1988). If this reorganization of synaptic connections is a consequence of axonal sprouting, Timm granules should develop in the supragranular region of the $D G$ early in the course of kindling in a time course compatible with axonal sprouting and growth. Furthermore, if mossy fiber synaptic reorganization has a role in the development and permanence of kindling, it should progress in parallel with the evolution of evoked seizures and become permanent when long-lasting susceptibility to kindling is established. In the present paper, we have tested these hypotheses with a scoring method that provided a more quantitative assessment of alterations in Timm histochemistry in the DG at a variety of time points in the evolution of kindling. Preliminary observations have been reported previously in abstract form (Cavazos et al., 1988).

\section{Materials and Methods}

\section{Kindling and surgical procedures}

Sprague-Dawley male rats $(250-350 \mathrm{gm})$ were anesthetized with pentobarbital $(60 \mathrm{mg} / \mathrm{kg}$, i.p.) and were stereotaxically implanted with an insulated stainless steel bipolar electrode for stimulation and recording. The electrode was implanted in the perforant path near the region of 
the angular bundle $(8.1 \mathrm{~mm}$ posterior, $4.4 \mathrm{~mm}$ lateral, $3.5 \mathrm{~mm}$ ventral from bregma), in the amygdala (1.5 $\mathrm{mm}$ posterior, $4.2 \mathrm{~mm}$ lateral, 8.8 $\mathrm{mm}$ ventral from bregma), or in the olfactory bulb ( $9 \mathrm{~mm}$ anterior, 1.2 mm lateral, $1.8 \mathrm{~mm}$ ventral from bregma). After a recovery period of 2 weeks, the unrestrained awake animals received twice-daily kindling stimulation ( $5 \mathrm{~d}$ per week) with a $1 \mathrm{sec}$ train of $62 \mathrm{~Hz}$ biphasic constant current $1.0 \mathrm{msec}$ square wave pulses. The stimulation was delivered at the lowest intensity that evoked an afterdischarge (AD) according to the following paradigm. The rats initially received kindling stimulation at intensities of $500,750,900$, and 1000 , to a maximal $1100 \mu \mathrm{A}$, or until an $\mathrm{AD}$ was evoked. On subsequent days, the rats received kindling stimulation with the intensity that initially induced $A D$. After three consecutive stimulations that evoked $\mathrm{AD}$, the stimulation intensity was reduced in steps of $1000,900,750,500,400,300,200$, and $150 \mu \mathrm{A}$ and then in $20 \mu \mathrm{A}$ steps below $150 \mu \mathrm{A}$. The electrocncephalogram and AD were recorded from the bipolar electrode, which could be switched to the stimulator by a digital circuit for the delivery of the kindling stimulation. The evoked behavioral seizures were classified according to standard criteria (Sutula and Steward, 1986).

\section{Experimental design}

Assessment of the relationship of mossy fiber synaptic reorganization to initiation of kindling stimulation. Histological evidence for reactive synaptogenesis after a variety of experimental lesions typically becomes apparent at 4-5 d after the lesion and reaches a maximum about $10 \mathrm{~d}$ later (Steward et al., 1974; Matthews et al., 1976a,b; Lee et al., 1977; Nadler et al., 1977a,b; Steward and Loesche, 1977; McWilliams and Lynch, 1979; Nadler et al., 1980a,b; Cotman et al., 1981; Steward et al., 1988). If the development of Timm granules in the supragranular region of the DG in association with kindling also indicates axonal sprouting of mossy fibers, one would predict that these histological alterations would become apparent in a time course consistent with axonal sprouting and growth (i.e., 4-5 d after the first kindling stimulation). Altcrnativcly, if the devclopment of Timm granules in the supragranular layer reflects stimulation-induced alterations of zinc content in the synaptic terminals that are normally present in this region, alterations in Timm staining might be observed acutely or within hours of the stimulation. To distinguish between these possibilities, rats received twice-daily kindling stimulation of the perforant path or the amygdala according to the above-described paradigm for $3 \mathrm{~d}$ and were examined with the Timm method $24 \mathrm{hr}$ after the last evoked seizure. A matched group of rats that experienced an equivalent number of ADs evoked by twice-daily kindling stimulation during the first $3 \mathrm{~d}$ of stimulation was examined histologically 1 week after the last evoked seizure.

Assessment of the relationship of mossy fiber synaptic reorganization to the progression of kindling. It was of interest to determine if repeated kindling stimulation evokes progressive histological alterations in the supragranular region of the DG and to assess the relationship of reorganization of the mossy fiber pathway to the behavioral evolution of kindling. To address these possibilities, rats received perforant path, amygdala, or olfactory bulb stimulation until 5-10 ADs, or 5, 10, 1530 , or 50-75 Class V seizures were evoked, and were examined histologically with the Timm method $18 \mathrm{hr}$ after the last evoked seizure. Three rats that experienced 120-220 Class V seizures evoked by olfactory bulb stimulation were also examined.

Assessment of the permanence of mossy fiber synaptic reorganization. To assess the permanence of mossy fiber synaptic reorganization at various stages of kindling, rats were examined with the Timm method 3-4 months after 5-10 ADs or after 5, 15-30, or 50 Class V seizures evoked by perforant path, amygdala, or olfactory bulb stimulation. Several rats from these groups were examined 8 months after the last evoked seizure.

Controls. Control groups consisted of normal age matched rats and unstimulated rats implanted with angular bundle electrodes for 3 months.

\section{Histological procedures}

At thc appropriate time, rats from experimental and control groups were deeply anesthetized and perfused transcardially with an aqueous solution of $500 \mathrm{ml}$ of $0.4 \%(\mathrm{w} / \mathrm{v})$ sodium sulfide, followed by $500 \mathrm{ml}$ of $1.0 \%(\mathrm{w} / \mathrm{v})$ paraformaldehyde $/ 1.25 \%(\mathrm{w} / \mathrm{v})$ glutaraldehyde solution. The brains were removed and left overnight in a $30 \%(\mathrm{w} / \mathrm{v})$ solution of sucrose in fixative. Horizontal 40 micron frozen sections were developed in the dark for 30-60 min in a 12:6:2 mixture of gum arabic $(20 \%$, w/v), hydroquinone $(5.6 \%, \mathrm{w} / \mathrm{v})$, citric acid-sodium citrate buffer with $1.5 \mathrm{ml}$ of a silver nitrate solution (17\%, w/v) (Danscher, 1981; Sutula et al., 1988). Alternate sections were stained with cresyl violet.

\section{Scoring methods for Timm histochemistry}

Mossy fiber synaptic reorganization was evaluated by rating the distribution of supragranular Timm granules in a standard horizontal section from the dorsal DG ipsilateral to the stimulating electrode (Fig. 1). The distribution of Timm granules in the supragranular region was rated on a scale of 0 to 5 according to the following criteria (see Fig. 2):

0 - no granules between the tips and crest of the DG

1 -sparse granules in the supragranular region in a patchy distribution between the tips and crest of the DG

2-more numerous granules in the supragranular region in a continuous distribution between the tips and crest of the DG

3 -prominent granules in the supragranular region in a continuous pattern between tips and crest, with occasional patches of confluent granules between tips and crests of the DG

4-prominent granules in the supragranular region that form a confluent dense laminar band between tips and crest

5 -confluent dense laminar band of granules in the supragranular region that extends into the inner molecular layer

In pilot studies, small variations in section thickness and development time for the Timm reaction did not significantly alter Timm scores. The interobserver variability for ratings generated with this scoring scale was about $9 \%$.

\section{Statistical analysis}

The pattern of Timm staining in a standard horizontal section of DG from the dorsal hippocampal formation was independently rated according to the above criteria by three observers who were blind to the identity and seizure history of each section. A Timm score was calculated for each section by averaging the independently derived scores of the three observers. Mean Timm scores for the experimental and control groups were calculated by averaging the Timm scores of the individual sections for each animal in the group. A nonparametric logistic regression demonstrated small residual errors in the scoring data that conformed to a Gaussian distribution (data not shown). This observation and other theoretical considerations including the central limit theorem, confirmed that analysis with parametric statistics was appropriate for the ordinal data derived from the scoring scale (Box et al., 1978). The data were therefore analyzed for statistical significance with a one-way ANOVA, and the differences between group mean scores were analyzed for significance with the Fisher's least significant difference test $(t$ test protected; Snedecor and Cochran, 1980).

\section{Results}

Relationship of development of mossy fiber synaptic reorganization to initiation of kindling stimulation

The mean Timm score from normal rats $(0.52 \pm 0.16, n=7)$ did not differ from electrode-implanted rats that were not stimulated $(0.52 \pm 0.18, n=9)$. These groups were therefore considered as a single control group for further statistical analysis $(0.52 \pm 0.12, n=16)$.

The mean Timm score of rats perfused $24 \mathrm{hr}$ after a single $\mathrm{AD}$ evoked by perforant path stimulation did not differ from control rats (see Table 1, compare Fig. $3, A$ vs. $B$, and Fig. $4 A$ ). The mean 'limm score of rats that experienced 5 ADs evoked by perforant path stimulation and were perfused $24 \mathrm{hr}$ later (day 4 of the paradigm) was $1.50 \pm 0.22(n=5)$ and differed from controls $(0.52 \pm 0.12, p<0.05$, Fig. $3 A, C)$. The mean Timm score of rats that experienced 5 ADs and were perfused 1 week after the last stimulation that evoked an afterdischarge (day 10 of the paradigm) was $2.44 \pm 0.24(n=6)$ and differed both from controls $(p<0.001$; see Fig. $3 A, D)$ and from rats perfused on day $4(p<0.05$; see Fig. $3 C, D)$. The development of mossy fiber synaptic reorganization in response to initiation of amygdala stimulation followed a similar trend (see Table 1). 


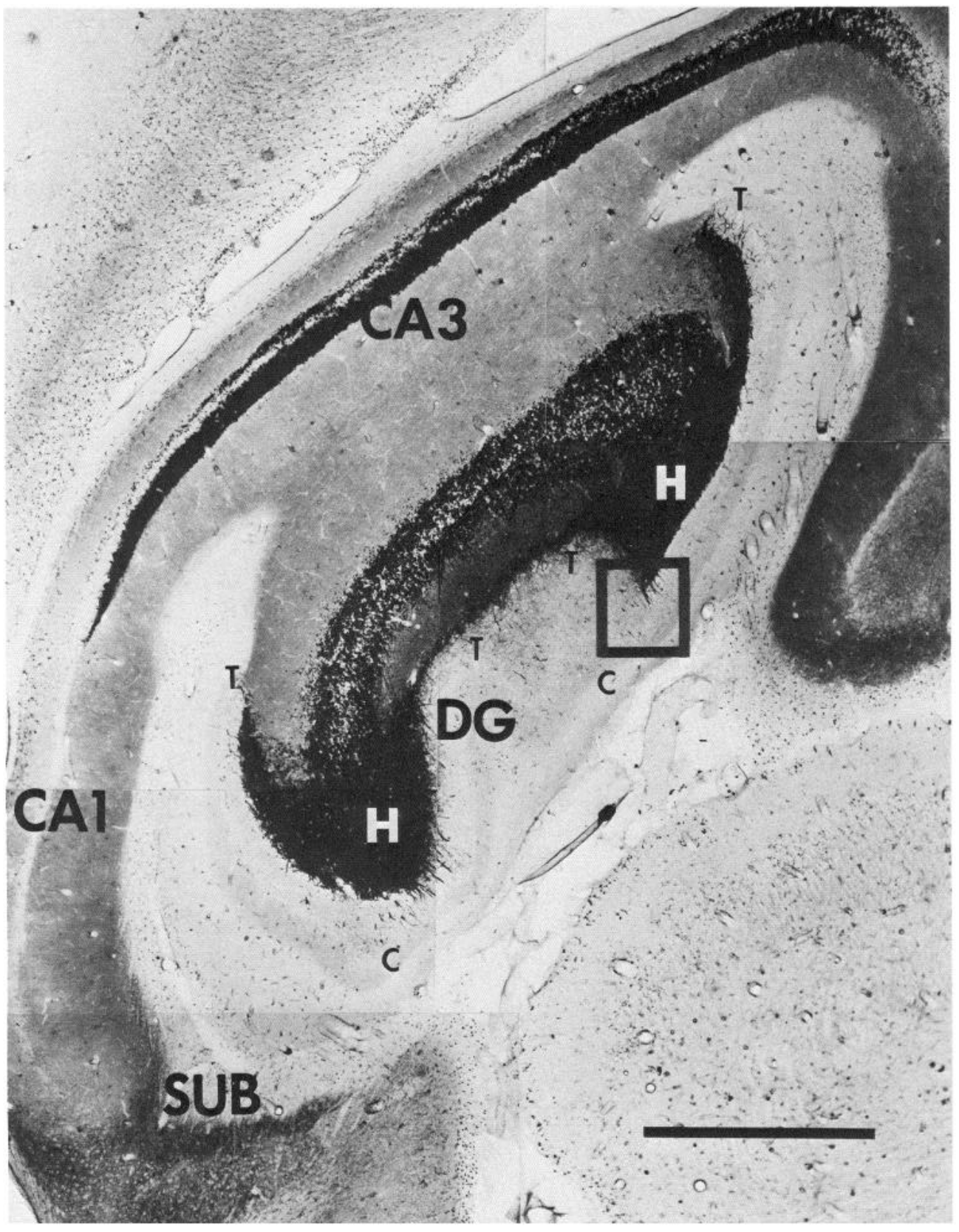

Figure 1. A representative horizontal Timm-stained section of the dorsal dentate gyrus of a normal rat demonstrates the location of the standard section examined in this study. The area in the black rectangle is shown at higher magnification in Fig. $3 A$. Abbreviations: $D G$, dentate gyrus; $S U B$, subiculum; $H$, hilus; $T$, tip of dentate gyrus; $C$, crest of dentate gyrus. Scale bar, 500 microns.

\section{Progression of mossy fiber synaptic reorganization with the} evolution of kindling

Mean Timm scores increased with increasing numbers of ADs and Class $\mathrm{V}$ seizures evoked by perforant path, amygdala, or olfactory bulb kindling stimulation (see Table 2 and Fig. $4 B$ ). After five perforant path-evoked Class $\mathrm{V}$ seizures, the mean Timm score was $2.00 \pm 0.49(n=4)$. After $10,20-30$, and $50-$ 75 perforant path-evoked Class $\mathrm{V}$ seizures, the mean Timm scores were $3.67 \pm 0.30(n=6), 4.17 \pm 0.10(n=4)$ (see Fig. $3 E)$, and $4.17 \pm 0.10(n=4)$, respectively.

There was a significant correlation of the Timm score with the number of $\mathrm{ADs}$ and Class $\mathrm{V}$ seizures. In the range $0-42$ ADs, there was a linear correlation of Timm score with number of ADs $(r=+0.91)$. In this range, there was also a significant, but weaker, correlation of Timm score with the number of Class $\mathrm{V}$ seizures $(r=+0.74)$. The mean Timm scores appeared to reach an asymptote after about 40 ADs (see Fig. $4 B$ ). As the specimens with prominent laminar patterns of Timm granules that extended into the inner molecular layer could at most receive the maximum score of 5 , this apparent asymptote may be merely an artifact of the scoring scale. There was a correlation of Timm score with the natural logarithm of the number of ADs $(r=+0.93)$ for the range 0-100 ADs. The mean Timm scores also increased with repeated seizures evoked by amygdala or olfactory bulb stimulation (see Table 2 ). In addition, there were differences in the septotemporal and ipsilateral-contralateral distributions of synaptic reorganization induced by perforant path, amygdala, and olfactory bulb kindling stimulation (data not shown; Sutula and Cavazos, 1989). 
Figure 2. Scoring scale for evaluation of mossy fiber synaptic reorganization in the supragranular layer of the dentate gyrus. The distribution of Timm granules in the supragranular region of a standard section of dorsal dentate gyrus was rated on a scale of $0-5$ according to the following criteria: 0 , no granules between the tips and crest of the DG; 1 , sparse granules in the supragranular region in a patchy distribution between the tips and crest of the DG; 2, more numerous granules in the supragranular region in a continuous distribution between the tips and crest of the DG; 3, prominent granules in the supragranular region in a continuous pattern between tips and crest, with occasional patches of confluent granules between tips and crests of the DG; 4 , prominent granules in the supragranular region that form a confluent dense laminar band between tips and crest; 5 , confluent dense laminar band of granules in the supragranular region that extends into the inner molecular layer. Examples corresponding to each rating of the scale are illustrated. The supragranular region is indicated by the arrow in the upper left panel corresponding to a score of 0 .
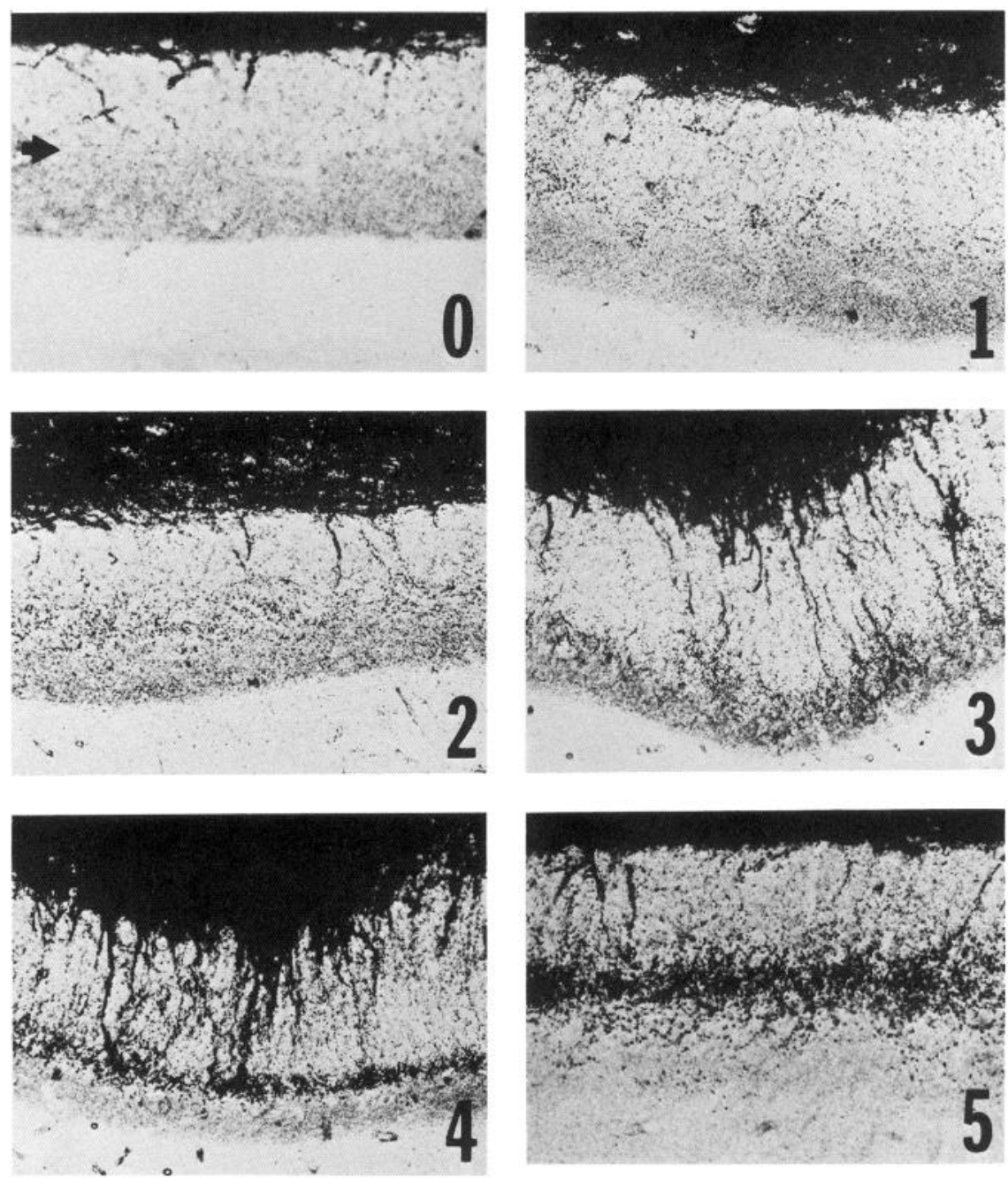

\section{Permanence of mossy fiber synaptic reorganization}

To assess the permanence of mossy fiber synaptic reorganization, groups of rats at different stages of kindling were killed and prepared for Timm histochemistry 3-4 months after the last evoked seizure. The mean Timm scores of rats perfused 3-

Table 1. Time course of development of early alterations in Timm histochemistry

\begin{tabular}{llr} 
Group & $\begin{array}{l}\text { Mean } \\
\text { Timm score } \\
( \pm \text { SEM })\end{array}$ & $n$ \\
\hline Perforant path & & \\
Controls & $0.52 \pm 0.12$ & 16 \\
1 AD, day 2 & $0.75 \pm 0.16$ & 4 \\
5 AD, day 4 & $1.50 \pm 0.22$ & $6^{a}$ \\
5 AD, day 10 & $2.44 \pm 0.24$ & $6^{b}$ \\
Amygdala & & 16 \\
Controls & $0.52 \pm 0.12$ & 2 \\
5 AD, day 4 & $1.17 \pm 0.17$ & 2 \\
5 AD, day 10 & $1.83 \pm 0.50$ &
\end{tabular}

Significant differences are footnoted.

${ }^{a} p<0.05$ versus controls.

${ }^{b} p<0.001$ versus controls; $p<0.05$ versus $5 \mathrm{ADs}-$ day 4 .
4 months or as long as 8 months after the last of $5,15-30$, or 50 Class V seizures evoked by perforant path stimulation did not differ from similar groups perfused $24 \mathrm{hr}$ after the last evoked seizure (see Table 2). Although the mean Timm score of rats examined 3-4 months after the last of five perforant path-evoked ADs $(1.26 \pm 0.32, n=5)$ was different from that of controls $(0.52 \pm 0.12, n=16)$, this difference did not achieve statistical significance. This result raises the possibility that some component of the alterations in Timm histochemistry (i.e., the zinc pool or the distribution of mossy fiber terminals) is partially reversible in the early stages of kindling.

\section{Discussion}

The scoring methods of this study confirmed previous observations about the development, progression, and permanence of mossy fiber synaptic reorganization induced by kindling. In addition, the study provided new details that are pertinent to the interpretation of changes in patterns of Timm histochemistry as indications of axonal sprouting and as possible mechanisms of kindling.

\section{Interpretation of alterations of Timm histochemistry as evidence of mossy fiber sprouting}

The time course of axon sprouting and reactive synaptogenesis after an intraventricular kainic acid injection, or other experi- 

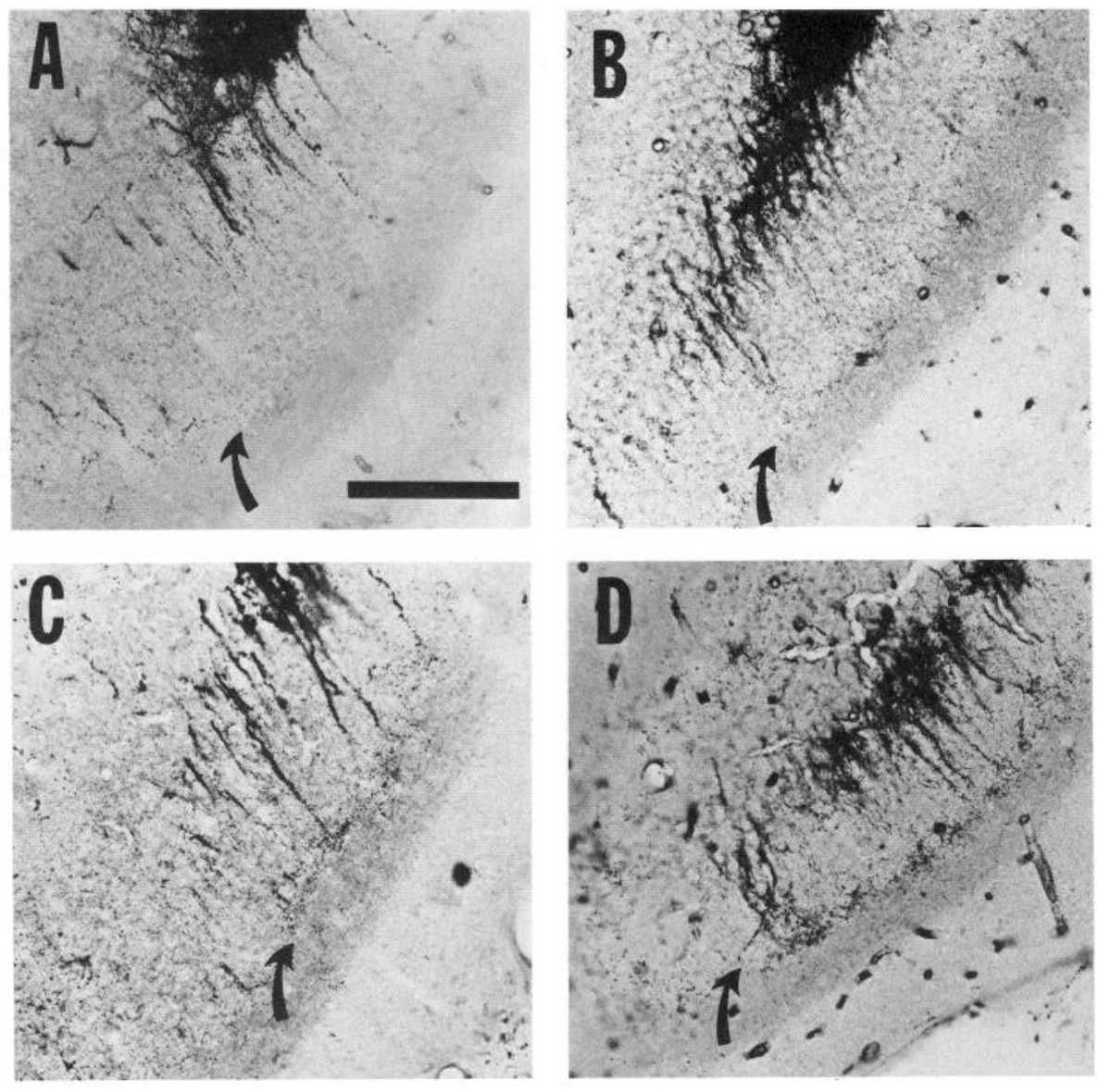

Figure 3. Time course of development and progression of mossy fiber synaptic reorganization in relation to initiation of kindling stimulation. $A$, Horizontal Timm-stained section of the dorsal dentate gyrus of a normal rat. Note the absence of Timm granules in the supragranular layer (arrow). Scale bar, $100 \mu \mathrm{m}$; same for panels $B, C, D$, and $E . B$, Representative horizontal section of the dorsal dentate gyrus of a rat that was examined with Timm histochemistry $24 \mathrm{hr}$ after a single afterdischarge. Note the absence of Timm granules in the supragranular layer (arrow). $C$, Representative horizontal section of the dorsal dentate gyrus of a rat examined with Timm histochemistry $24 \mathrm{hr}$ after the last of five afterdischarges evoked during the first $3 \mathrm{~d}$ of kindling stimulation. Sparse Timm granules are observed in the supragranular region (arrow). D, Representative horizontal section of the dorsal dentate gyrus of a rat examined with Timm histochemistry 1 week after the last of five afterdischarges evoked during the first $3 \mathrm{~d}$ of kindling stimulation. The Timm granules in the supragranular region are more prominent (arrow). E, Representative horizontal section of the dorsal dentate gyrus of a rat examined with Timm histochemistry $24 \mathrm{hr}$ after the last of 30 Class V seizures. The Timm granules in the supragranular region form a confluent dense laminar band (arrow).

mental lesions of hippocampal pathways, has been extensively characterized (Steward et al., 1974; Matthews et al., 1976a,b; Lee et al., 1977; Nadler et al., 1977a,b; Steward and Loesche, 1977; McWilliams and Lynch, 1979; Nadler et al.,1980a,b; Cotman et al., 1981; Steward et al., 1988). Terminal degeneration after lesions of hippocampal pathways typically is maximal about $3 \mathrm{~d}$ after induction of the lesion. Histological evidence for sprouting and reactive synaptogenesis is first apparent about 4$5 \mathrm{~d}$ after the lesion (McWilliams and Lynch, 1979; Nadler et al., 1980a), is nearly maximal about $10 \mathrm{~d}$ later, and is completed about $60 \mathrm{~d}$ after the lesion (McWilliams and Lynch, 1979). The time course of reactive sprouting and synaptogenesis by the mossy fiber pathway after lesions of polymorphic neurons in the hilus of the DG follows a similar time course (Nadler et al., 1980a). As kindling also induces neuronal loss in the hilus (Cavazos and Sutula, 1990), it might be expected that mossy fiber synaptic reorganization would develop with a similar time course after initiation of kindling stimulation.

In the present study, synaptic terminals of mossy fibers were identified by light microscopy as dark granules that correspond ultrastructurally to mossy fiber terminals (Sutula et al., 1988). These granules were not present in the supragranular region in significant numbers $2 \mathrm{~d}$ after the initiation of kindling stimulation but were apparent by day 4 and became increasingly prominent by day 10 . Thus, the time course of development of Timm granules during the early stages of kindling is similar to 


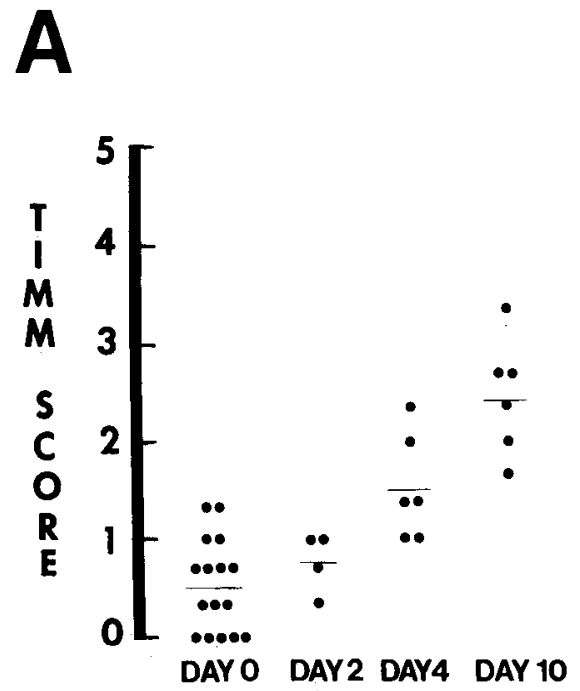

Figure 4. Timm scores of individual kindled rats as a function of evoked seizures. $A$, Plot of Timm scores of individual rats perfused on days $0,2,4$, and 10 after the initiation of kindling stimulation of the perforant path. Horizontal bars represent the group mean at each time point. Each dot corresponds to the mean score of each rat of the group, obtained from the individual scores of three examiners who were unaware of the identify and seizure history of the animal. The differences of group scores on days 4 and 10 were statistically significant (see Results). $B$, Plot of Timm scores of individual rats examined $24 \mathrm{hr}$ after the last evoked seizure as a function of the number of afterdischarges. Horizontal bars and dots correspond to group means and individual scores as in panel $A$. There was a significant correlation of Timm score and number of after discharges (sce Rcsults).
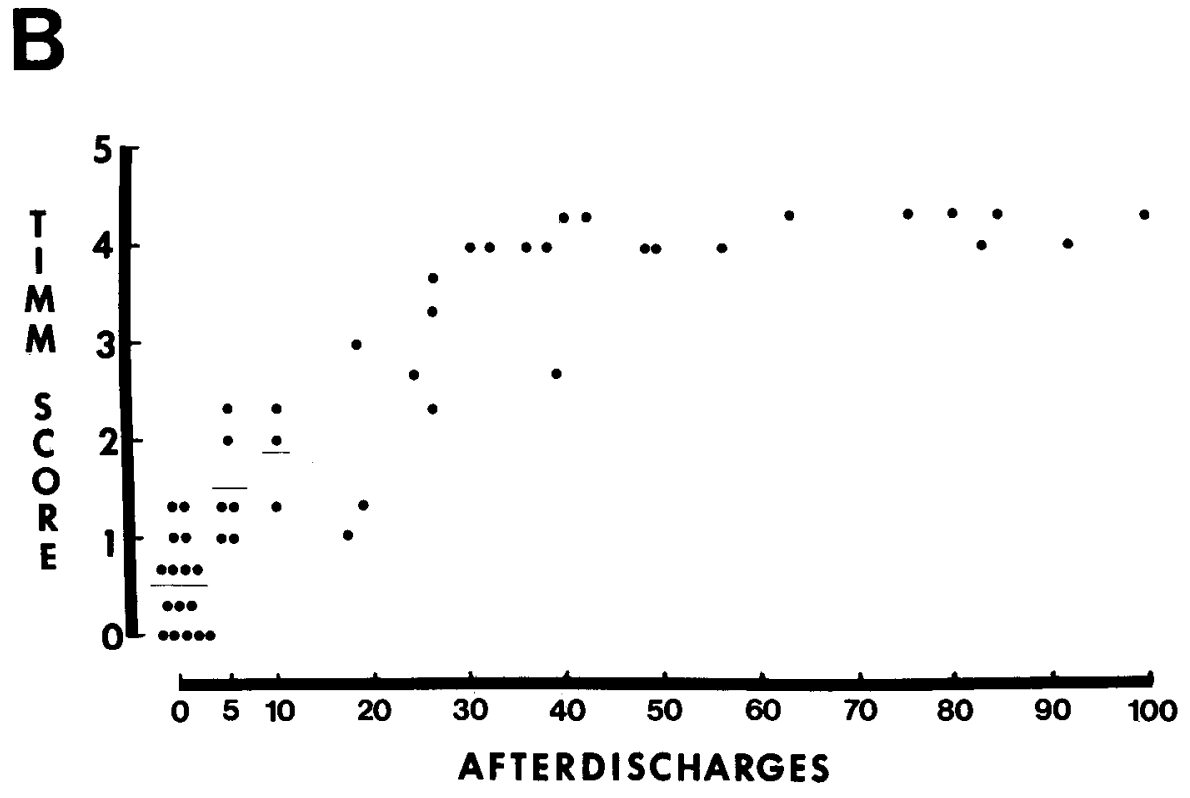

the time course of lesion-induced sprouting after hippocampal lesions and is consistent with the interpretation that the histological alterations induced by kindling are due to reactive sprouting and synaptogenesis by mossy fibers.

Other obscrvations with a varicty of histochemical and immunocytochemical markers of the mossy fiber pathway also support the interpretation that the mossy fiber pathway undergoes sprouting and reorganization of its synaptic connections in association with epileptic activity. In addition to Timm histochemistry (Sutula et al., 1989; Houser et al., 1990), other histological markers of mossy fibers, such as dynorphin and high affinity kainate receptors, have also been observed in the supragranular region of the DG in association with human epilepsy (de Lanerolle et al., 1989; Represa et al., 1989b; Houser et al., 1990). Thus, histological evidence derived with a variety of methods has revealed similar patterns of mossy fiber synaptic reorganization in both animal models (Sutula et al., 1988; Represa et al., 1989a; Golarai et al., 1989; Stanfield, 1989) and human epilepsy (de Lanerolle et al., 1989; Represa et al., 1989b; Sutula et al., 1989; Ben Ari and Represa, 1990; Houser et al.,
1990). On the basis of these previous observations and the current results that demonstrate a time course for development of Timm labeled synaptic terminals that is consistent with axonal sprouting, it appears likely that the alterations in Timm histochemistry induced by kindling and human epilepsy are due to sprouting of mossy fiber collaterals. These histochemical and immunocytochemical methods reveal the distribution of terminal and axonal projections but do not provide direct anatomical demonstration of collateral axon sprouting. More conclusive morphological evidence for mossy fiber sprouting could be obtained by examination of the pattern of axonal arborization of dye-filled granule cells after kindling.

\section{Mossy fiber synaptic reorganization as a mechanism of kindling}

The alterations in Timm histochemistry in the supragranular layer of the DG first developed 4-10 d after initiation of kindling stimulation and continued to progress with repeated seizures and the evolution of kindling. The results clearly demonstrated that the extent of mossy fiber synaptic reorganization in the 


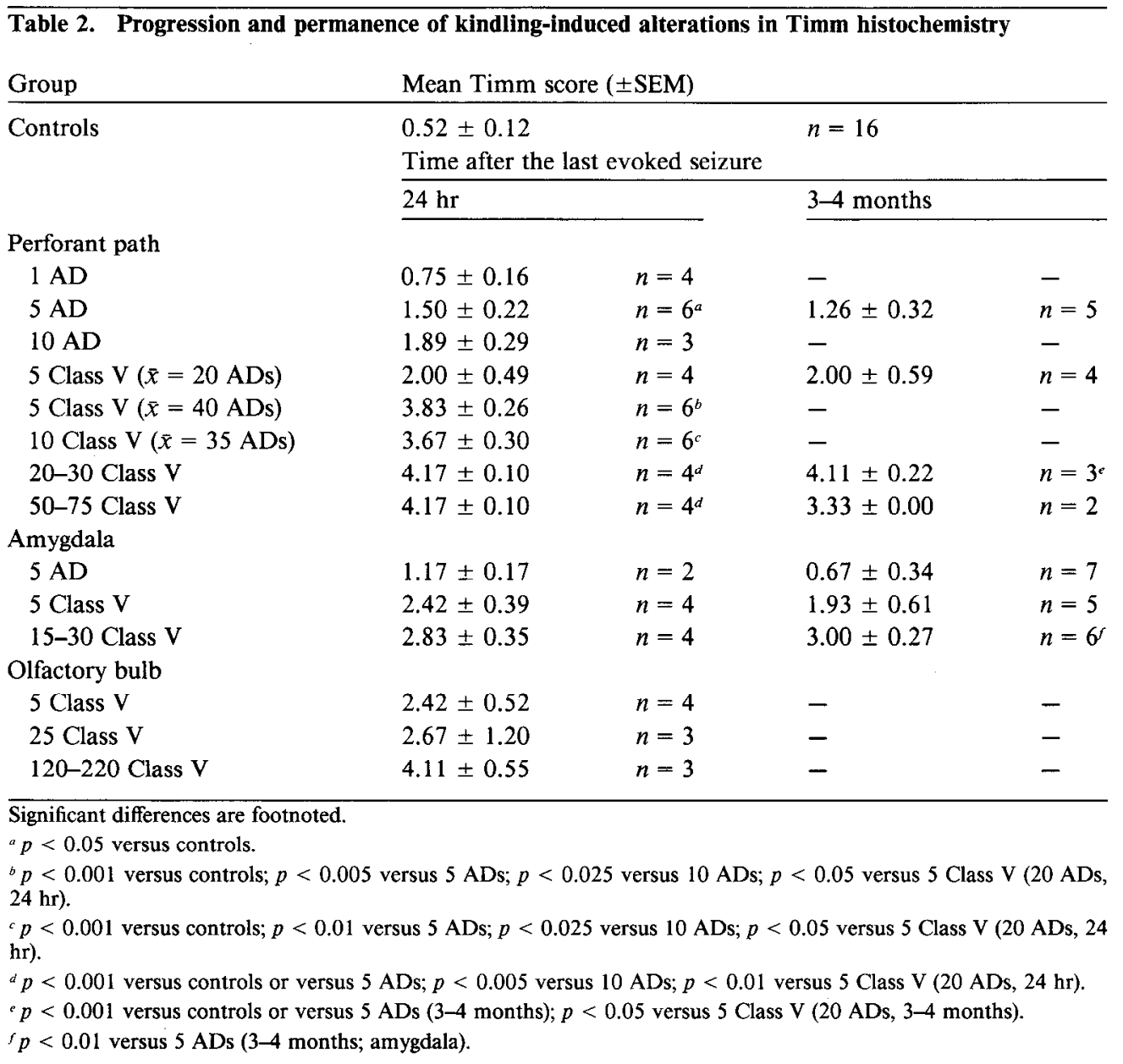

supragranular region of the dorsal DG correlated with two measures of kindling progression: (1) the number of ADs recorded from the stimulation site and (2) the stage or class of kindled seizures. As the duration of epileptic activation of the DG increases with increasing numbers of ADs evoked by either EC or amygdala kindling (Stringer et al., 1989; Stringer and Lothman, 1989), the results of this study can be interpreted as evidence of a direct correlation between the extent of mossy fiber synaptic reorganization and the duration of epileptic activity induced by kindling in local circuitry of the DG. There was also a correlation between mossy fiber sprouting and synaptic reorganization with the class of kindled seizures, i.e., the behavioral propagation of evoked seizures. Thus, there is a relationship between mossy fiber proliferation in the supragranular region with both duration of epileptic activity in local circuitry of the DG and propagation of evoked epileptic activity into distant circuitry.

Kindling induces permanent susceptibility to seizures (Goddard et al., 1969), and the present study demonstrated that synaptic reorganization of the mossy fiber pathway was present as long as 8 months after the last seizure. The results thus confirmed that mossy fiber synaptic reorganization is quite longlasting, if not permanent. Furthermore, as kindling stimulation delivered to a variety of sites induced synaptic reorganization of the mossy fiber pathway, the results also suggest that synaptic reorganization may be a "transsynaptic" alteration postulated in previous studies (Goddard et al., 1969; Messenheimer et al.,
1979) and could play a role in the phenomena of "transfer" noted in association with delivery of kindling stimulation to multiple sites (Goddard et al., 1969).

The observations of this study are consistent with the possibility that sprouting and synaptic reorganization of the mossy fiber pathway or other limbic pathways (Cavazos and Sutula, 1989) may play a role in the development, progression, and permanence of kindled seizures. In addition, the potential importance of mossy fiber synaptic reorganization as a cellular alteration in the DG that could play a role in the kindling phenomenon is further supported by other experiments that have implicated the DG as a structure that influences the development of kindling. Destruction of the DG by microinjection of colchicine or microsection of perforant path axons prior to kindling stimulation of amygdala or entorhinal cortex impairs the development of kindled seizures (Dashieff and McNamara, 1982; Savage et al., 1985; Frush et al., 1986; Sutula et al., 1986). In contrast, destruction of the $\mathrm{CA} 3, \mathrm{CA} 3$, or the hilus of the DG by kainic acid or electrolytic methods is followed by sprouting of the mossy fiber pathway and accelerates kindling development (Feldblum and Ackermann, 1987; Sutula et al., 1987). These experiments demonstrate that local circuitry of the DG plays a role in the development of kindling in response to activation of limbic pathways and are consistent with the possibility that mossy fiber synaptic reorganization induced by lesions or kindling stimulation is an alteration that could increase excitability in the DG. In support of this viewpoint, recent stud- 
ies have demonstrated that coadministration of phenobarbital with kainic acid suppressed the seizures induced by kainic acid, prevented neuronal degeneration in the hilus of the DG, reduced mossy fiber sprouting, and completely prevented the facilitating effect of prior kainic acid treatment on subsequent kindling (Sutula et al., 1990). The demonstration of mossy fiber synaptic reorganization in human epileptic patients (de Lanerolle et al., 1989; Represa et al., 1989a; Sutula et al., 1989; Houser et al., $1990)$ suggests that some of these observations could have clinical relevance.

The correlation between sprouting and synaptic reorganization of the mossy fiber pathway with the development, progression, and permanence of kindling strongly associates structural reorganization of hippocampal circuitry with the induction of an epileptic state by kindling. However, the present results do not distinguish whether sprouting and synaptic reorganization of the mossy fiber pathway is a cause or effect of repeated seizures. There is preliminary evidence that the synaptic terminals of sprouted mossy fiber axons may form synapses with dendrites of granule cells (Frotscher and Zimmer, 1983) and also with inhibitory interneurons (Ribak and Petersen, 1991). Characterization of the postsynaptic targets of synaptic terminals of the sprouted pathway is potentially important. Activation of sprouted collaterals that terminate on dendrites of granule cells would be expected to increase recurrent excitation in the DG, while activation of sprouted collaterals that terminate on interneurons could increase inhibition in the DG.

The specific functional effects of synaptic reorganization are still uncertain. Insight into the effects of axon sprouting and synaptic reorganization on hippocampal excitability and functional activity, and its possible role in the generation of epileptic events, will likely require experiments that combine electrophysiological methods with anatomical assessment of the sprouted pathway. The scoring methods described in this paper may be helpful in assessment of sprouting and synaptic reorganization of the mossy fiber pathway.

\section{References}

Amaral DG (1978) A golgi study of cell types in the hilar region of the hippocampus in the rat. J Comp Neurol 182:851-914.

Ben-Ari Y, Represa A (1990) Brief seizure episodes induce long-term potentiation and mossy fibre sprouting in the hippocampus. Trends Neurosci 13:312-318.

Blackstad TW (1963) Ultrastructural studies on the hippocampal region. In: Progress of brain research, Vol. 3 (Bargmann W, Schade JP, eds), pp 122-148. Amsterdam: Elsevier.

Blackstad TW, Kjaerheim A (1961) Special axo-dendritic synapses in the hippocampal cortex: electron and light microscopic studies on the layer of mossy fibers. J Comp Neurol 117:133-159.

Box G, Hunter WG, Hunter JS (1978) Statistics for experimenters: an introduction to design, data analysis, and model building. New York: Wiley.

Cavazos JE, Sutula TP (1989) Morphological evidence for synaptic reorganization induced by kindling in the stratum moleculare of the $\mathrm{CA} 1$ /subiculum transitional region of the rat hippocampal formation. Soc Neurosci Abstr 15:454.

Cavazos JE, Sutula TP (1990) Progressive neuronal loss induced by kindling: a possible mechanism for mossy fiber synaptic reorganization and hippocampal sclerosis. Brain Res 527:1-6.

Cavazos JE, Parada I, Sutula TP (1988) Mossy fiber synaptic reorganization develops and becomes permanent in parallel with the progression of kindling. Soc Neurosci Abstr 14:882.

Cotman CW, Nieto-Sampiedro M, Harris EW (1981) Synapse replacement in the nervous system of adult vertebrates. Physiol Rev 61:684-784.

Danscher G (1981) Histochemical demonstration of heavy metals: a revised version of the sulphide silver method suitable for both light and electronmicroscopy. Histochemistry 71:1-16.

Dasheiff RM, McNamara JO (1982) Intradentate colchicine retards the development of amygdala kindling. Ann Neurol 11:347-352.

de Lanerolle N, Kim J, Robbins R, Spencer D (1989) Hippocampal interneuron loss and plasticity in human temporal lobe epilepsy. Brain Res 495:387-395.

Feldblum S, Ackermann R (1987) Increased susceptibility to hippocampal and amygdala kindling following intrahippocampal kainic acid. Exp Neurol 97:255-269.

Frederickson CJ, Klitenick MA, Manton WI, Kirkpatrick JB (1983) Cytoarchitectonic distribution of zinc in the hippocampus of man and the rat. Brain Res 273:335-339.

Frotscher M, Zimmer J (1983) Lesion-induced mossy fibers to the molecular layer of the rat fascia dentata: identification of postsynaptic granule cells by the golgi-EM technique. J Comp Neurol 215:299311.

Frush DP, Giacchino JL, McNamara JO (1986) Evidence implicating dentate granule cells in development of entorhinal kindling. Exp Neurol 92:92-101.

Goddard G, McIntyre D, Leech C (1969) A permanent change in brain function resulting from daily electrical stimulation. Exp Neurol 25: 295-330.

Golarai G, Parada I, Sutula T (1988) Mossy fiber synaptic reorganization induced by repetitive pentylenetetrazol seizures. Soc Neurosci Abstr 14:882.

Houser C, Miyashiro J, Swartz B, Walsh G, Rich J, Delgado-Escueta A (1990) Altered patterns of dynorphin immunoreactivity suggest mossy fiber reorganization in human hippocampal epilepsy. J Neurosci 10:267-282.

Ibata Y, Otsuka N (1969) Electron microscopic demonstration of zinc in the hippocampal formation using Timm's sulfide-silver technique. J Histochem Cytochem 17:171-175.

Laurberg S, Zimmer J (1981) Lesion induced sprouting of hippocampal mossy fiber collaterals to the fascia dentata in developing and adult rats. J Comp Neurol 200:433-459.

Lee K, Stanford E, Coleman CW, Lynch GS (1977) Ultrastructural evidence for bouton proliferation in the partially deafferented dentate gyrus of the adult rat. Exp Brain Res 29:475-485.

Matthews DA, Cotman C, Lynch G (1976a) An electron microscopic study of lesion-induced synaptogenesis in the dentate gyrus of the adult rat. I. Magnitude and time course of degeneration. Brain Res 115:1-21.

Matthews DA, Cotman C, Lynch G (1976b) An electron microscopic study of lesion-induced synaptogenesis in the dentate gyrus of the adult rat. II. Reappearance of morphologically normal synaptic contacts. Brain Res 115:23-41.

McNamara J (1986) Kindling model of epilepsy. In: Basic mechanisms in epilepsy (Delgado-Escueta A, Ward A, Woodbury D, Porter R, eds), Advances in Neurology, Vol 44, pp 303-318. New York: Raven.

McNamara JO (1988) Pursuit of the mechanisms of kindling. Trends Neurosci 11:33-36.

McWilliams JR, Lynch GS (1979) Terminal proliferaiton in the partially deafferented dentate gyrus. J Comp Neurol 187:191-198.

Messenheimer JA, Harris EW, Steward O (1979) Sprouting fibers gain access to circuitry transynaptically altered by kindling. Exp Neurol 64:469-481.

Mody I, Stanton PK, Heinemann U (1988) Activation of $N$-methylD-aspartate receptors parallels changes in cellular and synaptic properties of dentate granule cells after kindling. J Neurophysiol 59:10331054.

Nadler IV, Cotman CW, Lynch GS (1977a) Histochemical evidence of altered development of cholinergic fibers in the rat dentate gyrus following lesions. I. Time course after complete unilateral entorhinal lesion at various ages. J Comp Neurol 171:561-588.

Nadler JV, Paoletti C, Cotman CW, Lynch GS (1977b) Histochemical evidence of altered development of cholinergic fibers in the rat dentate gyrus following lesions. II. Effects of partial entorhinal and simultaneous multiple lesions. J Comp Neurol 171:589-604.

Nadler JV, Perry B, Cotman C (1980a) Selective reinnervation of hippocampal area CAl and the fascia dentata after destruction of CA3-CA4 afferents with kainic acid. Brain Res 182:1-9.

Nadler JV, Perry B, Gentry C, Cotman C (1980b) Loss and reacquisition of hippocampal synapses after selective destruction of CA3-CA4 afferents with kainic acid. Brain Res 191:387-403. 
Perez-Clausell J, Danscher G (1985) Intravesicular localization of zinc in rat telencephalic boutons: an histochemical study. Brain Res 337: 91-98.

Pinel JP, Mucha RF, Phillips AG (1974) Spontaneous seizures generated in rats by kindling: a preliminary report. Physiol Psychol 3: $127-129$.

Represa A, Le Gal La Salle G, Ben-Ari Y (1989a) Hippocampal plasticity in the kindling model of epilepsy in rats. Neurosci Lett 99:345350

Represa A, Robain O, Tremblay E, Ben-Ari Y (1989b) Hippocampal plasticity in childhood epilepsy. Neurosci Lett 99:351-355.

Ribak CE, Petersen GM (1991) Intragranular mossy fibcrs in rats and gerbils form synapses with the somata and proximal dendrites of basket cells in the dentate gyrus. Hippocampus, in press.

Savage D, Rigsbee L, McNamara J (1985) Knife cuts of the entorhinal cortex: effects on development of amygdaloid kindling and seizureinduced decrease in muscarinic cholinergic receptors. J Neurosci 5: $408-413$.

Snedecor GW, Cochran WG (1980) Statistical methods. Ames, IA: Iowa State University.

Stanfield BB (1989) Excessive intra- and supragranular mossy fibers in the dentate gyrus of tottering $(\mathrm{tg} / \mathrm{tg})$ mice. Brain Res 480:294-299.

Steward O, Loesche J (1977) Quantitative autoradiographic analysis of the time course of proliferation of contralateral entorhinal efferents in the dentate gyrus denervated by ipsilateral entorhinal lesions. Brain Res 125:11-21.

Steward O, Cotman CW, Lynch GS (1974) Growth of a new fiber projection in the brain of adult rats: re-innervation of the dentate gyrus by the contralateral entorhinal cortex following ipsilateral entorhinal lesions. Exp Brain Res 20:45-66.

Steward O, Vinsant SL, Davis L (1988) The process of reinnervation in the dentate gyrus of adult rats: an ultrastructural study of changes in presynaptic terminals as a result of sprouting. J Comp Neurol 267: 203-210.
Stringer JL, Lothman EW (1989) Maximal dentate gyrus activation: characteristics and alterations after repeated seizures. J Neurophysiol 62:136-143.

Stringer JL, Williamson JM, Lothman EW (1989) Induction of paroxysmal discharges in the dentate gyrus: frequency dependence and relationship to afterdischarge production. J Neurophysiol 62:126135.

Sutula T, Cavazos J (1989) Regional variation in the distribution of mossy fiber synaptic reorganization induced by kindling: evidence for a relationship of synaptic reorganization to patterns of neural activity. Soc Neurosci Abstr 15:454.

Sutula TP, Steward O (1986) Quantitative analysis of synaptic potentiation during kindling of the perforant path. J Neurophysiol 56:732746.

Sutula TP, Harrison C, Steward O (1986) Chronic epileptogenesis induced by kindling of the entorhinal cortex: the role of the dentate gyrus. Brain Res 385:291-299.

Sutula T, He XX, Hurtenbach C (1987) Facilitation of kindling by CA3/CA4 lesions: evidence for epileptogenic potential of lesion-induced sprouting and synaptic reorganization. Epilepsia 28:947.

Sutula T, He XX, Cavazos J, Scott G (1988) Synaptic reorganization in the hippocampus induced by abnormal functional activity. Science 239:1147-1150.

Sutula T, Cascino G, Cavazos J, Parada I, Ramirez L (1989) Mossy fiber synaptic reorganization in the epileptic human temporal lobe. Ann Ncurol 26:321-330.

Sutula T, Cavazos J, Golarai G (1990) Brief treatment with phenobarbital alters long-term susceptibility to kindling after $\mathrm{CA} 3 / \mathrm{CA} 4$ lesions. Epilepsia 31:650.

Wada JA, Sato M, Corcoran ME (1974) Persistent seizure susceptiblity and recurrent spontaneous seizures in kindled cats. Epilepsia 15:465478. 